\title{
Discontinuous isoperibolic thermal analysis (DITA) (applied to organic components)
}

\author{
P. Marchand, L. Lefebvre, L. Courvoisier, G. Perez, J.-J. Counioux ${ }^{1}$ \\ and G. Coquerel
}

Unité de Croissance Cristalline et de Modélisation Moléculaire $\left(U C^{2} M^{2}\right)$, UPRES EA 2659, IRCOF, Université de Rouen, 76821 Mont-Saint-Aignan cedex, France

${ }^{1}$ Laboratoire d'Énergétique et de Synthèse Inorganique, UPRES A 5079 du CNRS, Université Claude Bernard Lyon I, 43 boulevard du 11 novembre 1918, 69622 Villeurbanne cedex, France

\begin{abstract}
The development of the Discontinuous Isoperibolic Thermal Analysis ( $\triangle \mathrm{ITA}$ ) aims at setting up a new phase diagram investigation technique efficient in the case of organic component systems. A heterogeneous system (with at least one liquid phase) is kept in isoperibolic conditions and submitted to discontinuous composition shifts by successive additions of a thermostated solvent (or solution). It results in perturbations of the equilibrium state and then physical phenomena which bring the system back to the equilibrium. The phenomena resulting from the addition of liquid (dissolution, dilution...) imply enthalpy changes which cause temperature variations of the system. An adapted exploitation of the temperature versus time signals leads to the determination of the topology of the corresponding phase diagram.
\end{abstract}

\section{INTRODUCTION}

Discontinuous Isoperibolic Thermal Analysis ( $\triangle \mathrm{ITA}$ ) is a new phase diagram investigation technique which has been developed from the Isoplethal Thermal Analysis (ITA) [1-4]. ITA is efficient in the investigations of the inorganic component systems but cannot be applied to organic components ; $\triangle \mathrm{ITA}$ has been especially designed to enlarge the field of investigations to these organic component systems. Although the heterogeneous equilibria [5-8] between organic components are usually rather simple when compared to those between inorganic components, the large number of phase diagrams to be investigated over compensates this relative simplicity. Thus the fine chemical industry is in great need to have a powerful and automated tool which can help in describing heterogeneous equilibria between organic components.

NB : a system in isoperibolic conditions is neither isothermal nor adiabatic but its direct environment is considered as being perfectly isothermal. 


\section{PRINCIPLE}

For any heterogeneous system : the appearance or the disappearance of at least one phase leads to a discontinuity of the physical properties of the system versus composition.

The reciprocal statement means that : the detection of a discontinuity in a physical property of the system versus composition reveals the appearance or the disappearance of at least one phase.

A phase appears or disappears (by changing the composition) if, and only if, a boundary has been crossed on the corresponding phase diagram. So by detecting discontinuities in the physical properties versus composition, it is possible to determine phase diagrams.

In the case of $\triangle \mathrm{ITA}$ the physical property monitored is temperature. Actually temperature variations of the system maintained in isoperibolic conditions due to discontinuous composition shifts. Each shift, performed by (quasi)instantaneous addition of solvent (or solution), brings suddenly the system out of equilibrium. The system evolves immediately towards a new equilibrium by means of physical transformations like dissolution, dilution, crystallization, etc...The enthalpy changes related to these transformations imply temperature variations. An adapted exploitation of the temperature versus time data leads to the detection of the corresponding discontinuities.

\section{EXPERIMENTAL}

\subsection{Compulsory experimental conditions}

Any $\triangle$ ITA experiment must be carried out in special conditions.

The heterogeneous system investigated must contain at least one liquid phase in sufficient quantity so that an efficient stirring can be applied (this in order to obtain a proper use of the temperature probe). The system must be kept in isoperibolic conditions. The solvent (or solution) added must be perfectly thermostated and its addition has to be performed as fast as possible. The very low magnitude temperature variations must be detected by a highly sensitive thermometer and recorded. In order to save time, the whole device must be automated.

\subsection{Experimental setup description (cf. figure 1)}

(A) : Isoperibolic conditions

The heterogeneous system is placed in a test tube, itself submerged in water in a double-wall linked to a thermostat. A large Dewar flask covers the double-wall to prevent thermal perturbation from the outside.

(B) : Thermostated solvent (or solution) added

The amount of solvent (or solution) added for each addition must be perfectly thermostated. It is brought to the system through several turns of a tube submerged in water in the double-wall (resident time at least two hours). The additions are performed by a syringe pusher which allows such fast and accurate additions.

(C) : Homogenization of the system

The system is simply magnetically stirred.

(D) : Temperature variations detection

A temperature probe linked to a high sensitive thermometer (resolution : $10^{-3} \mathrm{~K}$ ) provides the temperature versus time variations monitoring. Indeed the phenomena that occur with organic components systems imply very low temperature variations (typically some $10^{-2} \mathrm{~K}$ ).

(E) : Monitoring and automation

A computer performs the monitoring of the experiment (gathering of the temperature versus time data) and its automation (addition of solvent (or solution) by controlling the syringe pusher) thanks to an original program developed in our lab. 


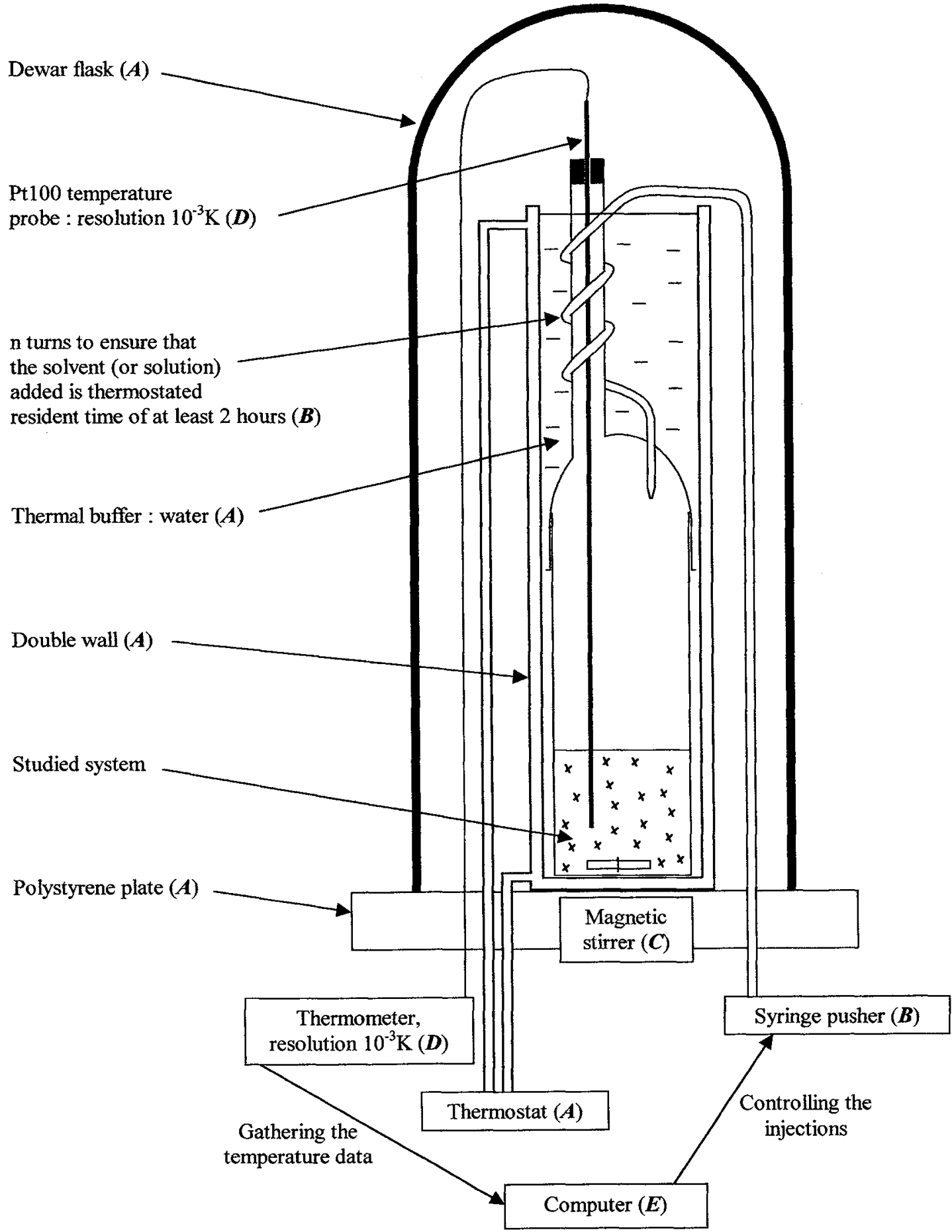

Figure 1. Experimental device schematic representation. 


\subsection{Experimental data after a single addition of solvent}

Each solvent (or solution) addition implies the recording of one elementary signal : the relative temperature of the system $(\Delta T)$ versus time $(t)$, in practice the temperature is recorded every second. A sudden temperature variation is followed by a slow spontaneous relaxation process. Practically a whole signal lasts about 20 minutes (cf. figure 2) and a total experiment is made of about 20 elementary signals.

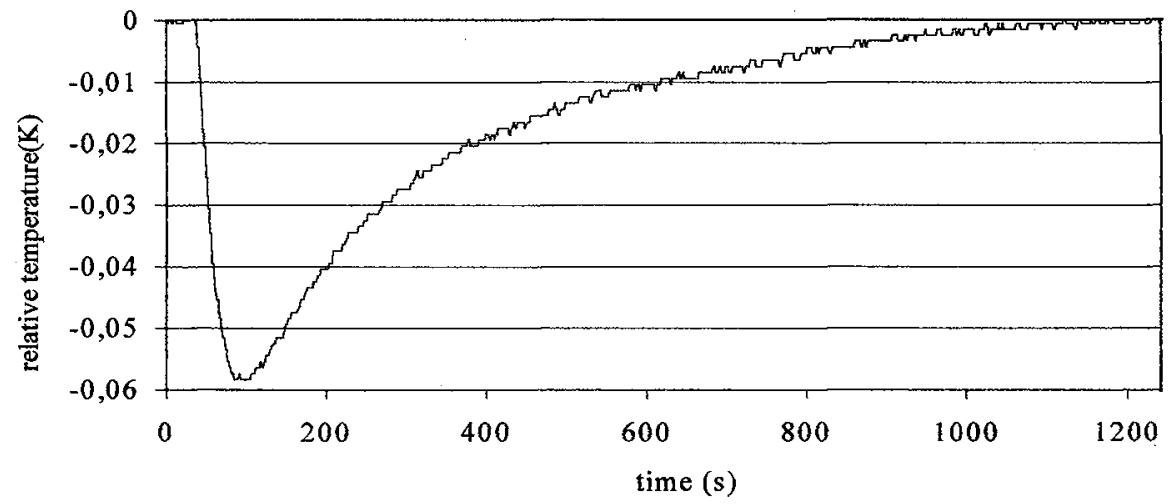

Figure 2. Typical elementary signal (case of a simple dissolution).

$N B$ : the relative temperature $\Delta T$ is defined as the difference between the temperature of the investigated system and its direct environment.

\section{EXPLOITATION}

\subsection{Theoretical interpretation}

During an elementary signal, two energy changes can be contemplated : the enthalpy exchanged $(\Delta H)$ due to the physical phenomena and the heat exchanged $(\mathrm{Q})$ due to the temperature difference between the system and its direct environment. The evolution of these energy changes versus time $(\Delta H(t)$ and $Q(t))$ can be related to the relative temperature of the system versus time $(\Delta T(t))$.

The limit conditions of the energy changes are easily expressed :

$\Delta \mathrm{H}(0)=0$ and $\Delta \mathrm{H}(+\infty)$ is the total enthalpy exchanged during the elementary signal

$\mathrm{Q}(0)=0$ and $\mathrm{Q}(+\infty)=-\Delta \mathrm{H}(+\infty)$

The relative temperature of the system can be related to the heat flow exchanged by the Newton's law : $\mathrm{dQ}(\mathrm{t}) / \mathrm{dt}=\mathrm{k} \cdot \Delta \mathrm{T}(\mathrm{t})$ where $\mathrm{k}$ is a time independent constant

The total integration of an elementary signal can be written :

$I==_{0} \int^{+\infty} \Delta T(t) \cdot d t$

according to (2) :

$\Delta \mathrm{T}(\mathrm{t}) \cdot \mathrm{dt}=-\mathrm{dQ}(\mathrm{t}) / \mathrm{k}$

$$
\begin{gathered}
\Rightarrow \mathrm{I}=-1 / \mathrm{k} \times{ }_{0}{ }^{+\infty} \mathrm{dQ}(\mathrm{t})=-1 / \mathrm{k} \times[\mathrm{Q}(+\infty)-\mathrm{Q}(0)] \\
\mathrm{I}=\Delta \mathrm{H}(+\infty) / \mathrm{k}
\end{gathered}
$$

This result does not depend on the nature, the number and the kinetics of the phenomena that occur.

\subsection{Exploitation}

According to (4), the integration value of an elementary signal is directly proportional to the enthalpy exchanged. So by plotting the cumulated integration values versus the composition of the system, slope disruptions can be detected by extrapolation and interpreted as discontinuities of the enthalpy changes versus composition. 


\section{PRACTICAL EXAMPLES}

Two examples are given below to illustrate the practical possibilities of $\triangle I T A$.

\subsection{Ternary system : enantiomer couple in a solvent}

The system studied is made of a couple of enantiomers $((+)$ and $(-)$ 5-(4'-methylphenyl)-5methylhydantoin, hereafter $17 \mathrm{H}$ ) and an organic solvent : $2 \mathrm{MeEtOH}$. The enantiomers crystallize as a conglomerate (cf. figure 3). All the analyses are performed at $298.15 \mathrm{~K}$.

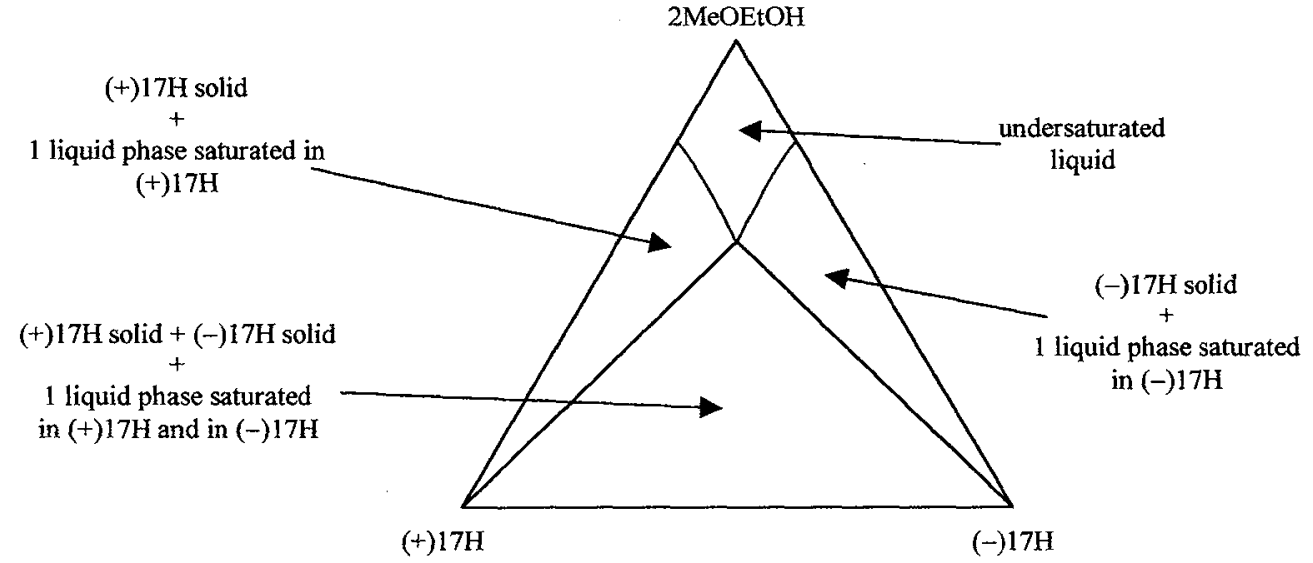

Figure 3. Isothermal section of the phase diagram of the system $( \pm) 17 \mathrm{H} / 2 \mathrm{MeOEtOH}$ (out of scale).

A first isoplethal section is performed by adding solvent to the pure enantiomer. One discontinuity is detected (cf. figure 4).

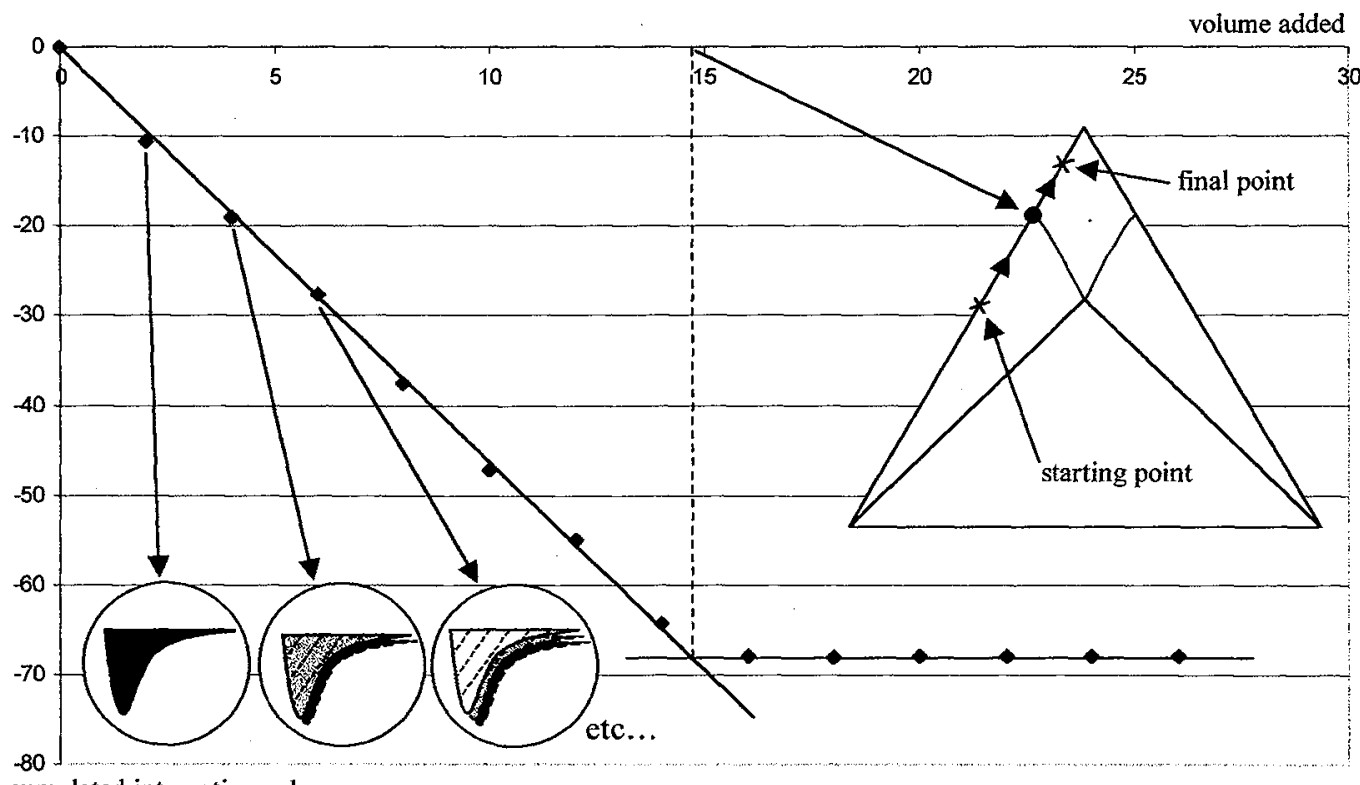

cumulated integration values

Figure 4. Exploitation plot, pure enantiomer/solvent isoplethal section. 
Second experiment : racemic mixture/solvent isoplethal section (cf. figure 5), one discontinuity detected.

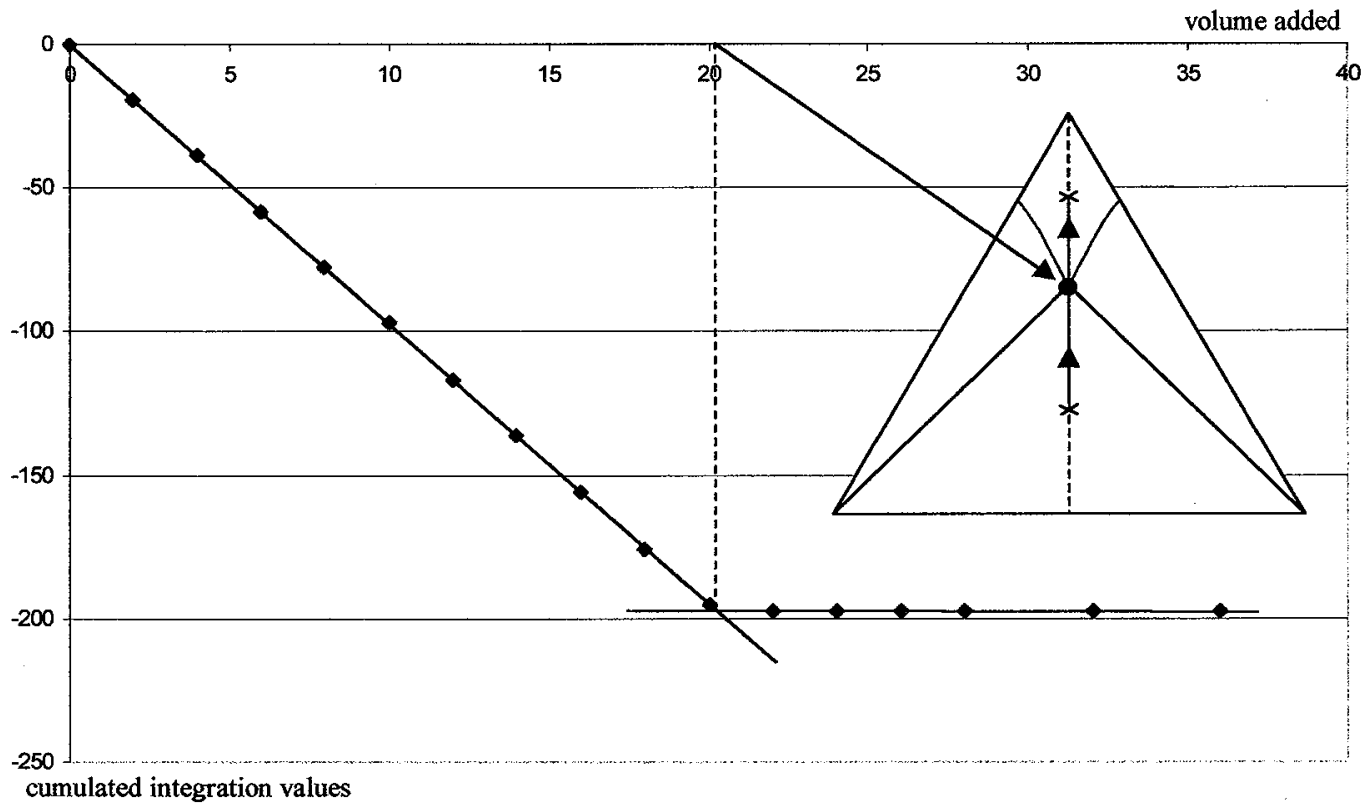

Figure 5. Exploitation plot, racemic mixture/solvent isoplethal section.

A third isoplethal section is performed by adding solvent to a $20 \%$ e.e. mixture (cf. figure 6 ). Two discontinuities are detected.

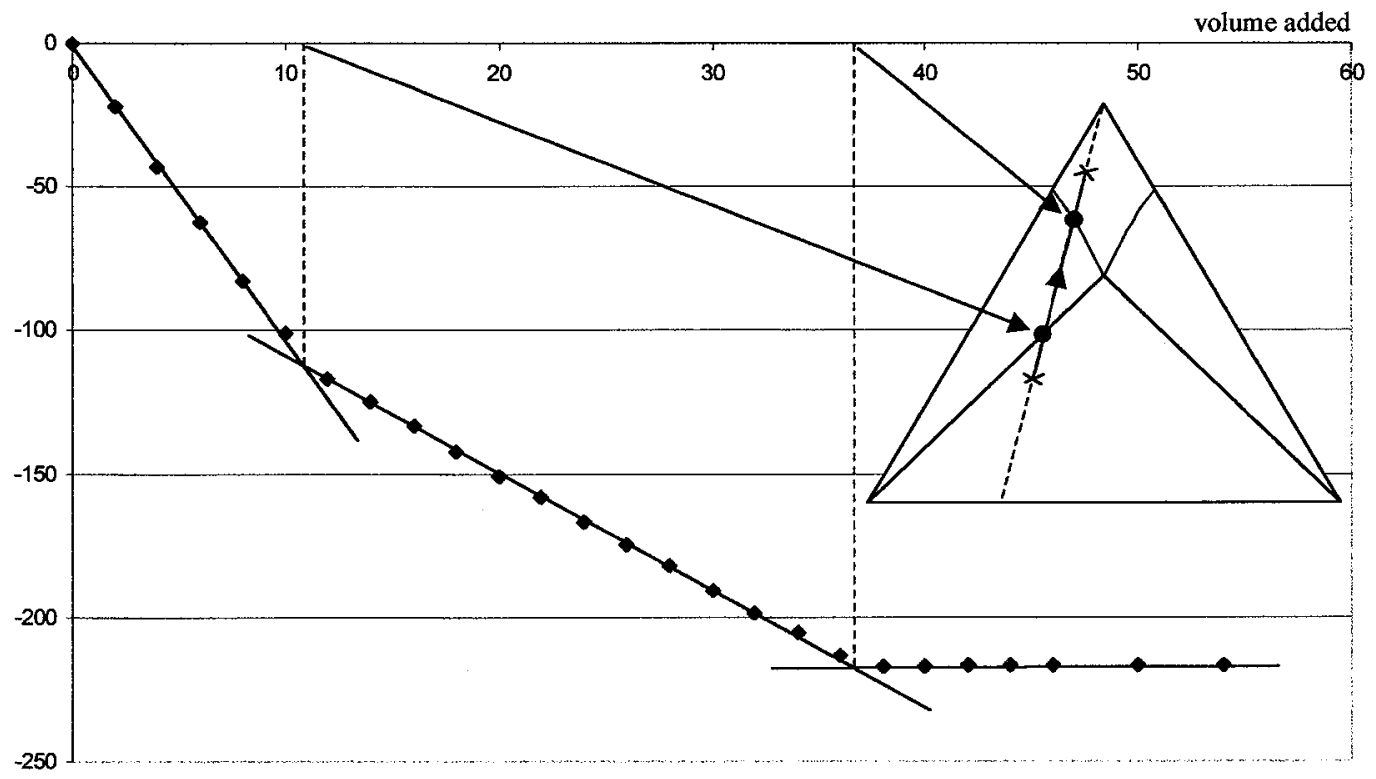

cumulated integration values

Figure 6. Exploitation plot, $20 \%$ e.e. mixture/solvent isoplethal section. 
These experimental results confirm the existence of the conglomerate, moreover the quantitative determination of the composition points on the phase diagram admits an error about $1 \%$ and fits well with the topological rules of phase diagrams.

\subsection{Binary system : miscibility gap of the water/phenol system}

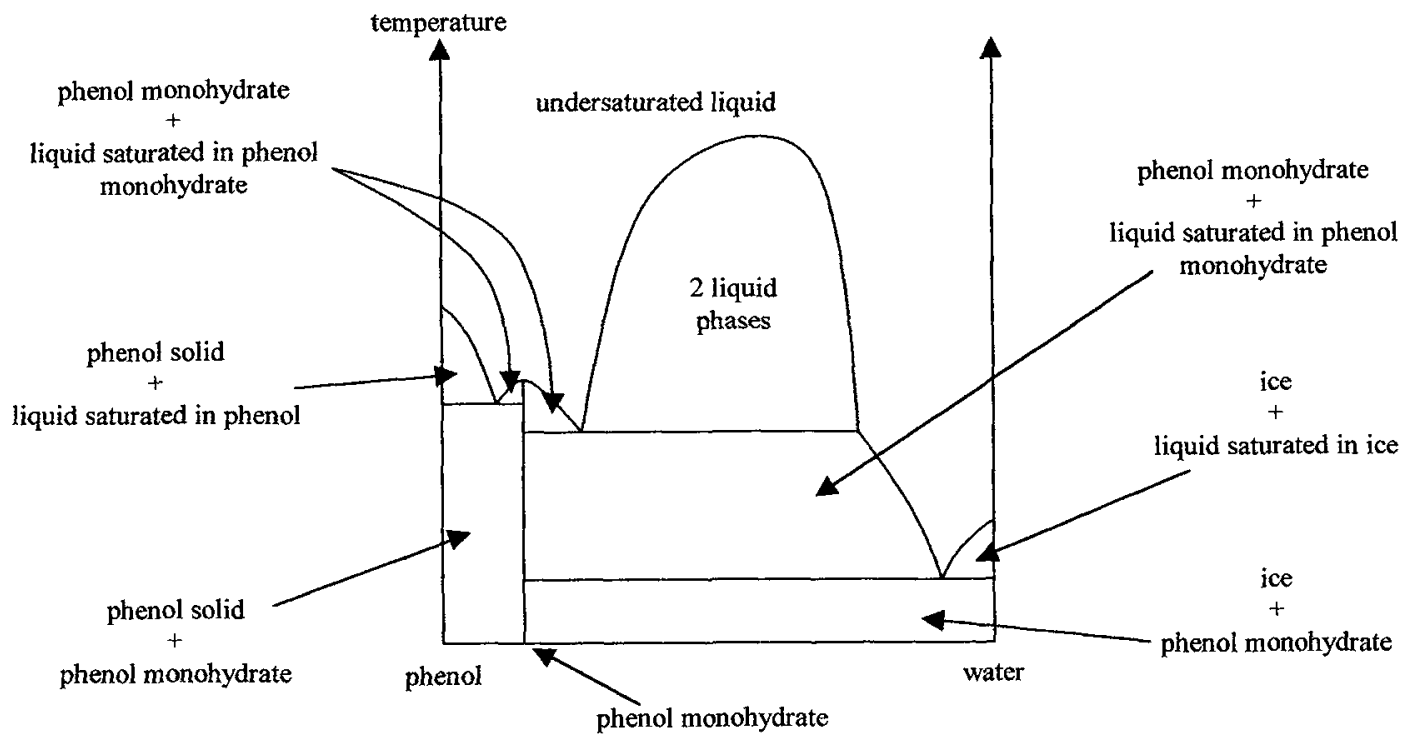

Additions of water are performed in the two ıqua pnase system.

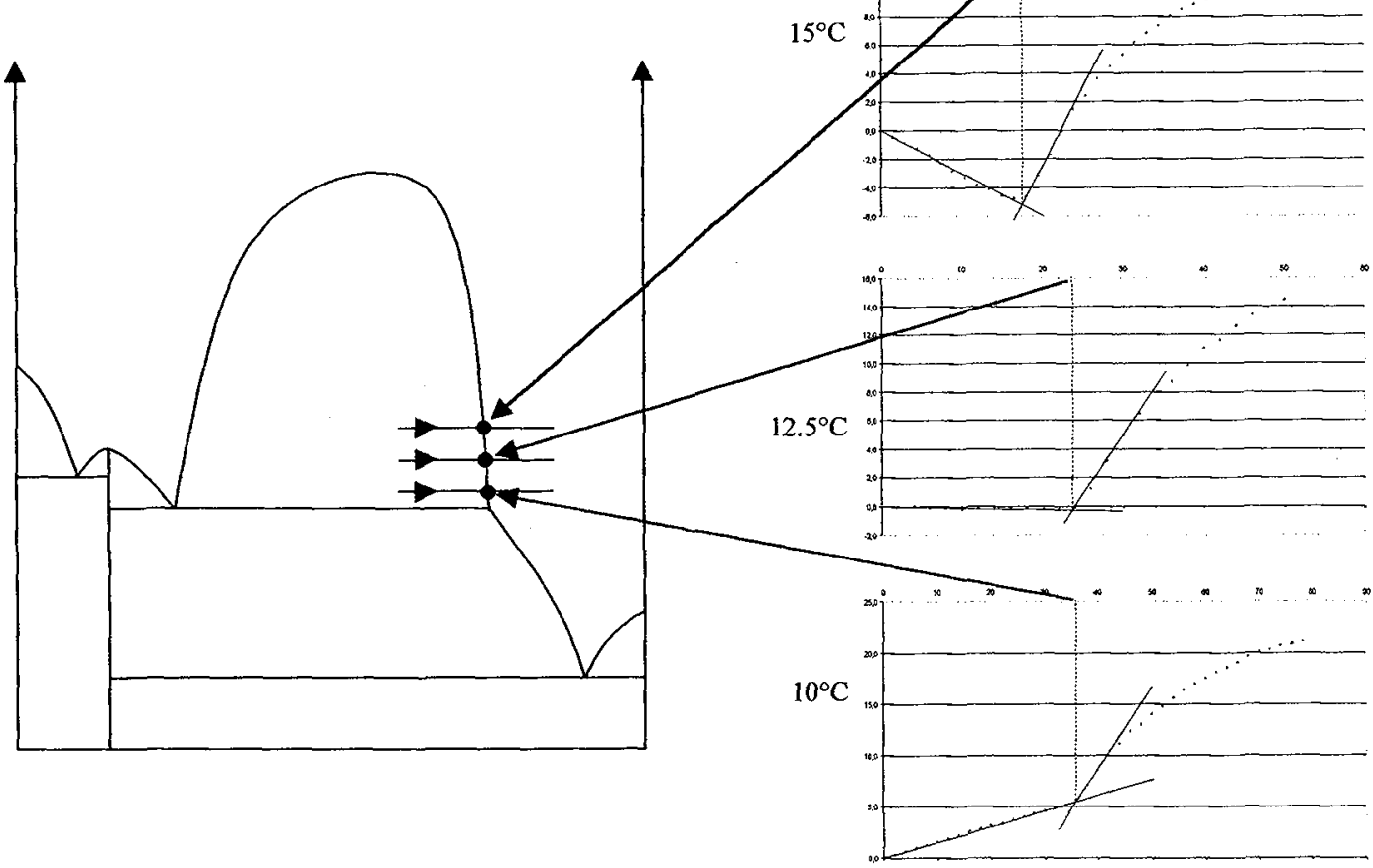


$\triangle$ ITA appears sensitive enough to detect liquid/liquid demixion. Moreover in the case of water phenol, an un expected change of sign of the heat exchange has been detected at $12.5^{\circ} \mathrm{C}$ in the liquid/liquid biphasic region.

\section{CONCLUSION}

The Discontinuous Isoperibolic Thermal Analysis ( $\triangle \mathrm{ITA}$ ) has proved to be an efficient tool in detecting and describing organic component heterogeneous equilibria by using a thermometer sensitive down to $10^{-3} \mathrm{~K}$. From the first experiments carried out, it appears that the raw signals are readily visible and the exploitation gives both accurate and consistent results. In the particular case of the water/phenol system the common thermal analysis (detection of inflexions in the cooling curves) is inefficient, the composition analysis of the liquid phases is an uneasy and long process which implies perturbations of the system due to sampling. $\triangle \mathrm{ITA}$ allows to perform the whole experiment in situ with almost no perturbation. This technique is designed to be used with other complementary techniques like XRPD or HPLC for the qualitative determination of the phases.

From these promising results :

1. new campaigns of tests will be performed, including more complicated systems (quaternary, quinary...) [9]

2. advanced mathematical treatments will be carried out

3. enhancement of the sensibility of the technique will be tested by using a $+/-10^{-4} \mathrm{~K}$ temperature probe [10].

\section{References}

[1] Berthet J., Saïd J. and Counioux J.-J., "Etude des Equilibres Solide-Liquide par Thermométrie QuasiIsotherme", XVII ${ }^{\text {èmes }}$ Journées d'Etudes des Equilibres entre Phases, Utrecht (NL), april 1991, edited by H.A.J. Oonk (University of Utrecht, 1991) pp. 195-198.

[2] Berthet J. and Counioux J.-J., french patent B.F. $n^{\circ} 9313$ 402, UCBL, (4 novembre 1993).

[3] Berthet J. and Counioux J.-J., "Bases Théoriques de l'Analyse Thermique Isopléthique", XX ${ }^{\text {èmes }}$ Journées d'Etudes des Equilibres entre Phases, Bordeaux, march 1994, edited by Y. Haget and A. Marbeuf (University of Bordeaux I, 1994) pp. 239-242.

[4] Berthet J. and Counioux J.-J., "Mise en Evidence par Analyse Thermique Isopléthique d'une Série de Nouveaux Composés : les Chlorures Mixtes de Calcium et d'Ammonium Hydrates", XXII ${ }^{\text {èmes }}$ Journées d'Etudes des Equilibres entre Phases, La Garde, april 1996, edited by J. Musso, P. Satre and A. Sebaoun (Université de Toulon et du Var, 1996) pp. 138-141.

[5] Schreinemakers A. H., Die Heterogenen Gleichgewichte Vom Standpunkte Phasenlehre (H.W. Backhuis Editor, Braunschweig, vol. III, 1911 part. 1 and 1913 part. 2).

[6] Ricci J. E., The Phase Rule and Heterogeneous Equilibrium (Dover Publications Inc., New York, 1966).

[7] Hillert M., Phase Equilibria, Phase Diagrams and Phase Transformations (Cambridge University Press, 1998).

[8] Coquerel G., Enantiomer 5 (2000) 481 498.

[9] Szalkai I., Journal of Mathematical Chemistry 25 (1999) 31-46.

[10] Brice L. K., Journal of Chemical Education 60(5) (1983) 387-389. 